\title{
Maximizing Motorway Capacity Through Hard Shoulder Running: UK Perspective
}

\author{
P. Chase ${ }^{\mathrm{a}}$ and E. Avineri ${ }^{*}, \mathrm{~b}$ \\ ${ }^{a}$ Atkins Ltd, Bristol, UK. The study was undertaken while the first author was at the University of the West of England, \\ Bristol, UK \\ ${ }^{b}$ University of the West of England, Bristol, UK
}

\begin{abstract}
New innovative ways to increase the capacity of motorways in the UK, without the need for substantial landtake and construction, are currently being developed by the Highways Agency (HA). One of these methods is Hard Shoulder Running (HSR), piloted on the M42 from late 2006. Based on interviews and content analysis of media reports, conducted before the piloting of the M42 scheme, this paper outlines the strengths and limitations of HSR as viewed by UK stakeholders. The paper considers the potential impact of the portrayal of HSR in the media, and discusses the informational requirements of UK drivers, paying attention to attitudes and behavior. It is concluded that there are a number of potential limitations to HSR, but relatively few reasons why HSR cannot potentially become successful and acceptable in the UK, as long as the correct level of information and driver education is provided.
\end{abstract}

Keywords: Hard shoulder running (HSR), motorway capacity, active traffic management (ATM).

\section{INTRODUCTION}

The UK is faced with a major challenge in the transport sector: The demand for road-based travel has soared in the last decade, and is expected to rise over time as the UK's population and economy grows and changes [1]. Despite assuming road-building equivalent to around an additional 3,500 Highway Agency lane kilometers, the UK's National Transport Model [2] forecasts road congestion to increase by 30 per cent on 2003 levels by 2025. It was realized in the 1998 transport White Paper, 'A New Deal for Transport' [3] that the UK's road network is largely complete, and that building new roads has failed to reduce congestion; instead, the management of existing roads has now been prioritized over building new ones.

The capacity of a road is often defined as the maximum number of vehicles which can pass a point in a given time, usually measured in vehicles per hour. In the UK, motorway lanes are designed to carry a maximum of between approximately 1100 (rural) and 1900 (urban) vehicles per hour, depending on the total number of lanes in each direction $[4,5]$. Therefore, motorway traffic capacity can be increased through provision of additional running lanes.

The 'hard shoulder' is an additional surfaced area of a motorway, usually 3.3 meters wide, adjacent to the carriageway edge, which serves a number of purposes, for example as an emergency refuge, as a space to perform lateral avoidance maneuvers, and as a temporary extra lane during road maintenance [6]. It may also assist in relation to achieving the desired horizontal sight distances and road structural

*Address correspondence to this author at the Centre for Transport \& Society, Faculty of Environment \& Technology, University of the West of England, Bristol, BS16 1QY, UK; E-mail: Erel.Avineri@uwe.ac.uk support (ibid.). 'Hard Shoulder Running' (HSR), however, implies that this additional road space is used to carry normal traffic rather than acting as an emergency reserve, thereby increasing the overall capacity of the motorway. The road network is characterized by periods of peaky demand, outside of which there is often spare capacity. A main objective of HSR would be to increase road capacity during peak-hour times as an alternative to building new roads, and with relatively small investment in infrastructure.

Serious consideration of HSR in the UK first appeared in the 1998 transport White Paper, 'A New Deal for Transport' and the accompanying ' $A$ New Deal for Trunk Roads in England' $[3,7]$. These documents suggested that maintenance and more efficient use of existing road space were to be prioritized over road building. In order to 'make better use' of existing road capacity, the Highways Agency (HA) began to develop a 'toolkit' of measures, involving 'new and innovative ways of managing and improving the trunk road network' [3]. The trunk road 'toolkit' includes techniques such as dedicated bus and High Occupancy Vehicle (HOV) lanes, MIDAS technology ${ }^{1}$, HSR, 'tiger tail' anti-swooping markings, and variable speed limits, as well as ramp metering. The measures in the 'toolkit' which use intelligent transport systems or manual operator intervention to control traffic flow are termed 'active traffic management' (ATM) techniques [8]. These ATM techniques are now a central part of road transport policy in the UK, with a detailed pilot recently taking place on the M42 in the West Midlands at a cost of approximately $£ 100$ million $^{2}$, aiming to reduce congestion and improve the reliability of journey times, improve re-

\footnotetext{
${ }^{1}$ MIDAS is Motorway Incident Detection and Automatic Signaling, operated by induction loops in the carriageway that can detect slow moving traffic and activate variable message signs accordingly.

${ }^{2}$ In comparison, the cost of widening this $17 \mathrm{~km}$ stretch of motorway has been estimated at $£ 450$ million [9].
} 


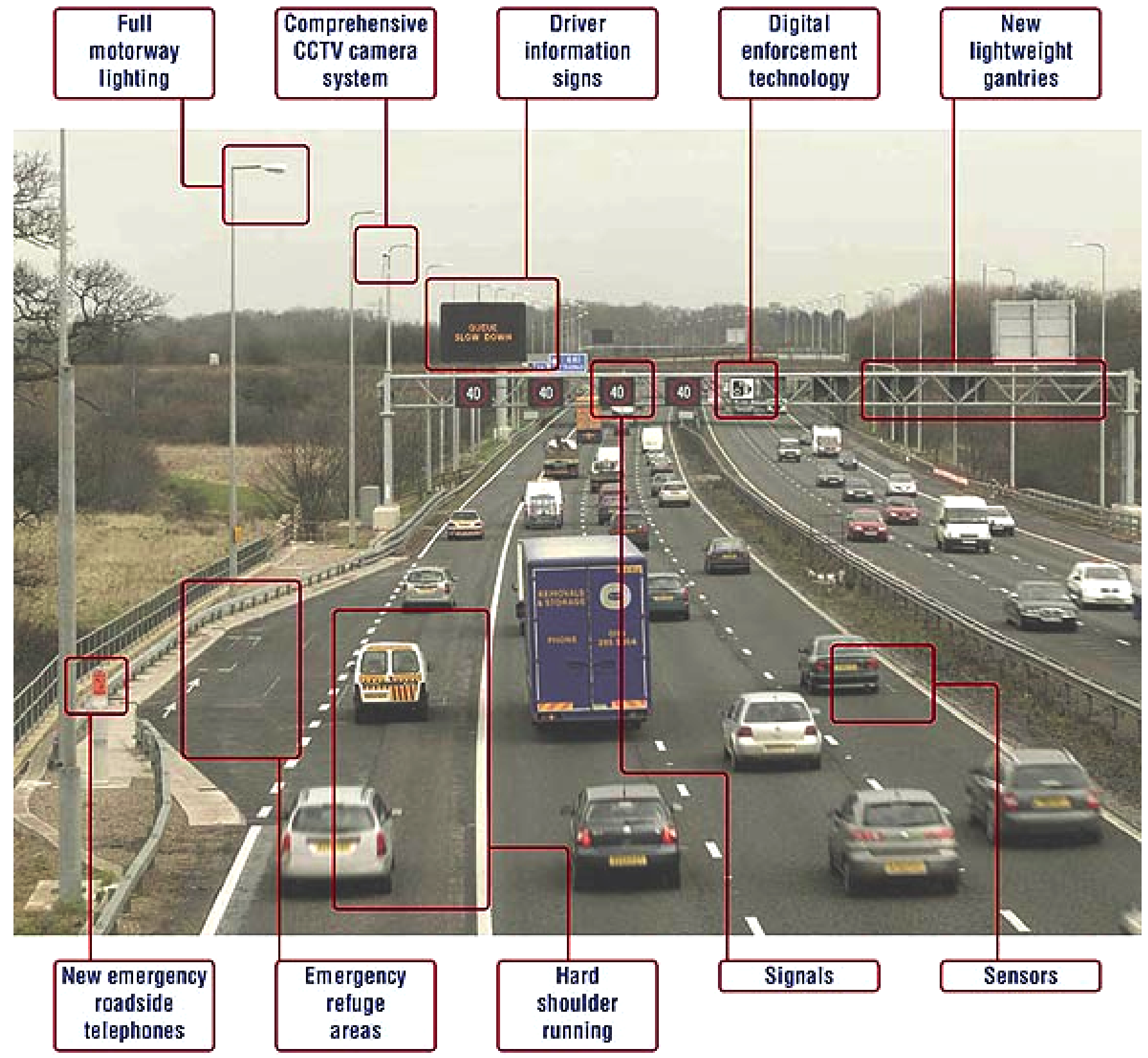

Fig. (1). Features of the M42 Active Traffic Management pilot. Source: HA (2004) [9]. Photograph courtesy of the Highways Agency.

sponse times to incidents, enhance driver information, and reduce driver stress. The main features of the M42 ATM pilot are shown in Fig. (1).

Controlled HSR has been planned to be operational between motorway junctions, with the status indicated by overhead Advanced Motorway Indicators (AMIs) and Signs (AMSs). Under normal flow conditions, all AMIs and AMSs will be blank and the national speed limit applies, with the hard shoulder reserved for emergency use only (Fig. 2a). When the volume of traffic increases, as detected by the MIDAS induction loops buried in the carriageway, such that $70 \mathrm{mph}$ is not a safe achievable speed, AMIs display a reduced speed limit, although the hard shoulder will remain closed (Fig. 2b). As the likelihood of flow breakdown increases, the hard shoulder is opened through displaying a speed limit on the AMIs (Fig. 2c). Prior to HSR operation, the ATM operator makes a visual CCTV check to ensure the hard shoulder is clear from obstructions and, when HSR is operational, the maximum speed limit on all lanes will be $50 \mathrm{mph}$. HSR is, arguably, the most controversial aspect of the M42 ATM pilot project, as it alters the purpose for which hard shoulders were originally designed and the role they have played on UK motorways since 1958.

\section{LITERATURE REVIEW ON HARD SHOULDER RUNNING}

Outside the UK, the experience of the Netherlands is that which is most commonly cited in UK documentation on ATM, and which appears to be most similar to the M42 pilot. Analyses conducted following the 1996 commencement of Dutch HSR, with seven sections totaling $25 \mathrm{~km}$ now in use $[10,11]$, have revealed congestion and accident density re- 
ductions. The UK National Audit Office [11, pp.4] has also identified the safety benefits of schemes in the Netherlands, in relation to stating why, in their criticism of the HA for failing to introduce innovative congestion reduction measures, there are 'no insurmountable obstacles to addressing safety concerns'.

Elsewhere, research on pilot HSR examples provides more varied results, although some slightly different HSR arrangements exist. In Göttingen (Germany) there is a static traffic-jam-valve, whereby drivers are signed to use the hard shoulder $1 \mathrm{~km}$ prior to the exit at a fixed peak time, and in Holdorf dynamic display panels indicate whether the $1 \mathrm{~km}$ section can be used, dependent on traffic levels [12]. For the A1 Westautobahn between Salzburg and Vienna (Austria), Berger and Maurer [13] conducted a cost-benefit analysis to ascertain under what circumstances the opening up of emergency lanes for driving is economically advisable. The use of HSR on the A6 in Cologne is reported by Kellermann [14]; conclusions of these studies are summarized in Table $\mathbf{1 .}$

(a) Normal motorway conditions

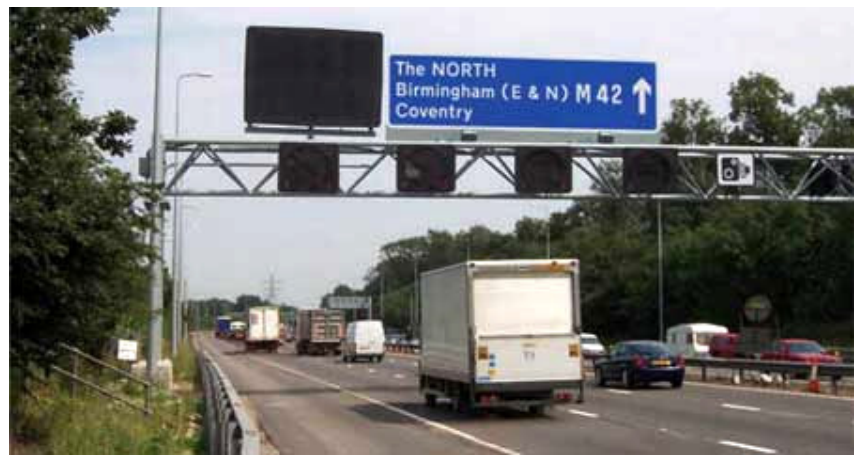

(b) Active Traffic Management without hard shoulder running:

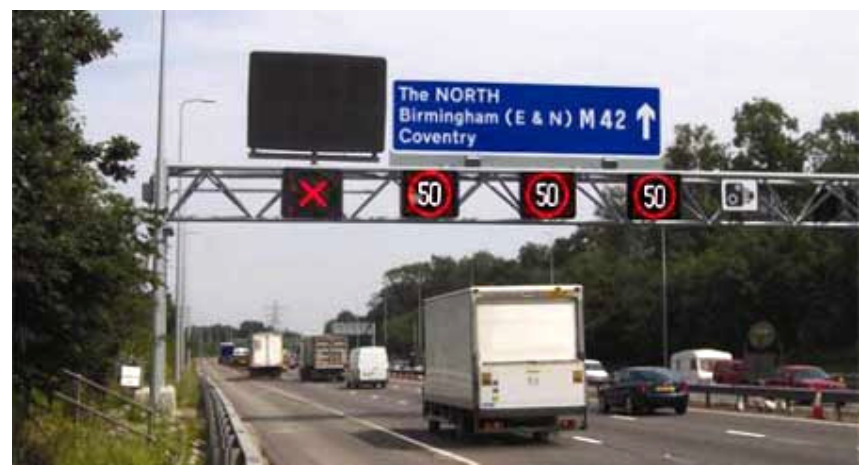

(c) Active Traffic Management with hard shoulder running

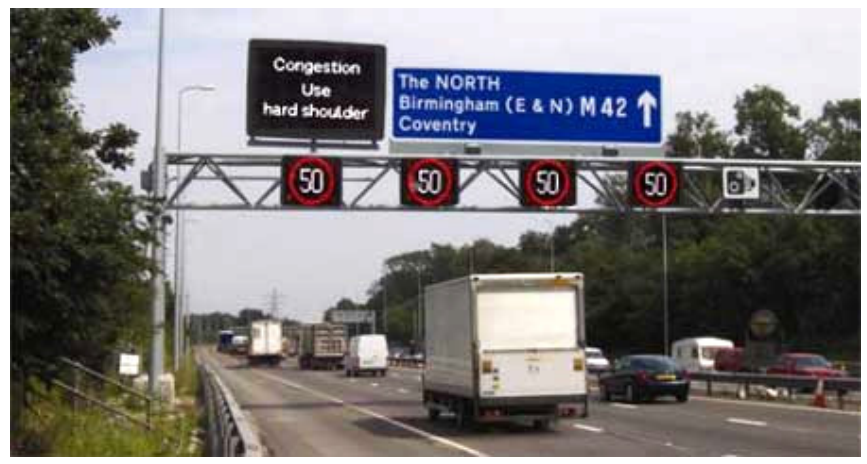

Fig. (2). UK Hard Shoulder Running operational regime. Source: HA (2004) [9]. Photographs courtesy of the Highways Agency.
The US Department of Transportation has recently produced a summary report [15] on previous and new research analyzing the benefits of converting the hard shoulder to a running lane. The research outlined again provides mixed results, with one freeway segment experiencing statistically significant increases in accident rates, and others significant reductions. However, in the USA, most hard shoulder conversions have been to HOV lanes, resulting in greater speed differentials between HOV and all other lanes during congested periods (ibid.). These speed differentials do not exist with UK HSR, as the hard shoulder is opened only during periods of heavy congestion and is for use by all vehicles, regardless of occupancy levels. Results from US research are therefore of limited use in investigating the appropriateness of HSR in the UK.

In previous research studies, 'success' of HSR schemes has been measured using a number of different parameters, often relating to accident occurrence and motorway safety overall, with infrastructure cost also recognized as important. Furthermore, even after detailed cost-benefit analyses, many of the results obtained within research papers are stated as not statistically significant [12-15], and there are no standard parameters used to measure (likely) 'success'. Additionally, an element of uncertainty exists in research into the potential for, and success of, HSR schemes outside the UK. This makes difficult the transferability of research findings to the UK pilot scheme.

Table 1. Summary of Key Previous Research Findings

\begin{tabular}{|c|c|}
\hline Research Findings 'For' HSR & Research Findings 'Against' HSR \\
\hline $\begin{array}{c}\text { Congestion frequency fell by } \\
\text { between } 68 \% \text { and } 82 \% \text { and } \\
\text { average car speeds (same traffic } \\
\text { volume) rose by } 9 \% \text { (Keller- } \\
\text { mann, 2000) [14] }\end{array}$ & $\begin{array}{l}\text { Temporal restrictions should not be } \\
\text { applied to traffic-jam-valves, due to } \\
\text { observed disregard and high capital } \\
\text { and operational costs (Shahin et al., } \\
\text { 2003) [12] }\end{array}$ \\
\hline \multirow{2}{*}{$\begin{array}{l}\text { Slight decrease in most relevant } \\
\text { accident characteristics follow- } \\
\text { ing installation of traffic-jam- } \\
\text { valves in Germany (Shahin } \\
\text { et al., 2003) [12] } \\
\text { Congestion-induced accidents } \\
\text { sunk considerably on A6 in } \\
\text { Cologne (Kellermann, 2000) } \\
{[14]}\end{array}$} & $\begin{array}{c}\text { Slight increase in accidents occur- } \\
\text { ring when vehicles change lanes on } \\
\text { A6 in Cologne (Kellermann, 2000) } \\
{[14]}\end{array}$ \\
\hline & $\begin{array}{l}\text { Hard shoulder conversions may } \\
\text { decrease upstream accident frequen- } \\
\text { cies, but lead to increases within and } \\
\text { downstream as a result of bottleneck } \\
\text { relocation (USDT, 2005) [15] }\end{array}$ \\
\hline $\begin{array}{l}\text { Best cost-benefit relationship } \\
\text { achieved with hard shoulder } \\
\text { open only under high traffic } \\
\text { volumes, with a reduced speed } \\
\text { limit and variable message signs } \\
\text { (Kellermann, 2000) [14] }\end{array}$ & $\begin{array}{l}\text { The increasing accident rate with } \\
\text { emergency bays far exceeds the } \\
\text { infrastructure and user cost savings } \\
\text { (Berger \& Maurer, 1999) [13] } \\
\text { Abandonment of emergency lanes } \\
\text { on motorways in Austria will not } \\
\text { benefit national economy when flow } \\
\text { exceeds 10,000 vehicles per day } \\
\text { (Berger \& Maurer, 1999) [13] } \\
\text { N.B. flow is approximately 120,000 } \\
\text { vehicles per day on the M42 pilot } \\
\text { section. }\end{array}$ \\
\hline $\begin{array}{l}\text { Alteration of a 3-lane carriage- } \\
\text { way to } 4 \text { lanes could reduce } \\
\text { accident rate by } 5 \% \text { (Berger \& } \\
\text { Maurer, 1999) [13] }\end{array}$ & $\begin{array}{l}33 \% \text { increase in accident rate can be } \\
\text { expected on motorways without an } \\
\text { emergency lane (Berger \& Maurer, } \\
\text { 1999) [13] }\end{array}$ \\
\hline
\end{tabular}


Revealed in the literature are some possible pitfalls of HSR. Shahin et al. [12] found that temporal restrictions were often disregarded, as well as the signed speed limits. Effective education on HSR will be of importance if, as Whitelaw [16] reports, the HA may switch off the system if people refuse to use it properly. This demonstrates the relationship between HSR and driver behavior. Shahin et al. [12] also noticed some 'unsteady driving maneuvers' at the end of the opened hard shoulder (where it meets the exit slip) in the Göttingen case study; this was seen to be a result of confusing lane markings. Confusion is possible in the UK, as a result of change to the historic role of the hard shoulder as an emergency lane. A counter-claim by TRL is that a substantial number of stops made on the hard shoulder are discretionary, such as comfort stops and vehicle checks, many of which could be eliminated with hard shoulder removal [17].

Using an evidence base primarily derived from HSR studies outside the UK to conclude that HSR will be appropriate in the UK may prove misleading; traffic flow benefits may be similar, but this does not necessarily mean road safety impacts will be comparable. The Parliamentary Advisory Council for Transport Safety (PACTS) has expressed concerns [18] that the evidence base is limited to the overseas experience. Also, research on public support for HSR, which is arguably a necessary pre-requisite for increasing its use across the motorway network, was almost non-existent in the UK at the time of this study, along with studies on the relationship between driver education or information and HSR; the HA has indeed stated that driver education is vital [16]. Similarly, driver behavior is seldom mentioned in HSR research, although Shahin et al. [12] identified it as an important influence on the 'success' of schemes.

The appropriateness of HSR for assisting in the alleviation of motorway congestion in the UK cannot be adequately assessed without further research. In particular, research is required into stakeholder and public support, including the role of driver education and behavior in both being influenced by, and acting as an influence on, such support. The next section describes the research methodology developed to gain and explore stakeholders' views on HSR before it was piloted on the M42.

\section{RESEARCH METHODOLOGY}

Overall, this research project developed with a flexible research design, as the research objectives required the important subjective issues surrounding HSR to be addressed, many of which could not be appreciated until information gathering had commenced. The research was based largely on data collection methods generating qualitative data and did not aim to test any hypothesis on the likely success of HSR in the UK, but aimed to reveal the likely 'acceptability' of HSR as a technique.

In order to gain an appreciation of stakeholders' viewpoints, semi-structured interviews were conducted with six organizations (see Table 3). Due to confidentiality agreement, some stakeholder organizations are not identified by their names. The primary purpose of the interviews was to reveal the experiences of stakeholders in relation to the daily operation of the UK motorway network, identifying any potential strengths or weaknesses of HSR from their position.
The stakeholders interviewed in the study are those representing road users (such as the haulage industry representative) and those who commonly work on the highway (such as the emergency services). Besides this certain type of stakeholder there are other interested parties who can add to the HSR debate:

(a) Local residents - they may actually benefit as HSR increases motorway capacity and reduces diversion onto alternative, less appropriate, local routes adjacent to the motorway.

(b) Environmental groups - while representatives of environmental groups were not approached and interviewed in this study, the benefits and limitations of HSR in environmental terms are discussed in the next section.

Besides interviews, a further element of this research was gathering texts for performing a media content analysis, in order to assess the ways in which the general public are made aware of the nature and purpose of HSR trials. The subsequent quasi-statistical content analysis used a scoring scale to assess attitude strength evident within the various media discourses. As newspaper articles tend to be formed of short focused sentences, the 'sentence' (where it was clearly related to ATM or HSR) was the recording unit. Categories and sub-categories were defined, along with a framework for analysis by which the recording units could be coded. The over-arching categories stemmed from the requirements for addressing the research objectives; the focus of attention and portrayal of HSR needed to be identified. Unit codes were aggregated within each category to form the overall analysis for each document.

\section{RESEARCH EVIDENCE: STAKEHOLDER OPINION AND MEDIA CONTENT ANALYSIS}

The key potential strengths and limitations of the UK approach to HSR, as identified by stakeholders during interviews and from stakeholders' websites, were analyzed through the use of theme matrices, with the following theme headings emerging from interview transcript analysis.

STRENGTHS: congestion relief; economic and resource benefits; potential for accident reduction as a result of traffic flow regulation; fewer merge and diverge traffic maneuvers; gradual AMI sequencing.

LIMITATIONS: emergency access; breakdown safety; altering the role of the hard shoulder; reactions of ATM technology to incidents; AMI/S reliability; 'cheap' investment; driver compliance; driver confusion and habitual behavior; overhead signage confusion; other causes of confusion; increased driver stress levels; HSR relationship with demand management.

All six of the interviewed stakeholder organizations recognized the capacity increase and (likely) congestion reduction benefits of implementing HSR; this was the most often cited reason behind the introduction of HSR in official HA documentation.

Consideration of the impact of UK HSR on accident occurrence is something which members of the three emergency services were keen to discuss. However, along with PACTS (Parliamentary Advisory Council for Transport 
Safety), they suggested that there is some potential for accident reduction, although the reasoning behind such assertions varied. For example, the police representative suggested that an extra lane could reduce collisions; Berger and Maurer [13] similarly claimed that by adding an additional lane to a 3-lane carriageway, the accident rate could be reduced by $5 \%$. The two interviewees representing the fire service argued that the motorway should be safer as a result of more constant traffic flows (reducing the stop-start wave syndrome). However, it could be claimed that this will be more attributable to the presence of variable speed limits than HSR itself; the safety of UK HSR indeed relies on other complementary measures, as is the case in the Netherlands.

The proposed HSR variable signing on gantries 500 meters apart is viewed as a strength by the police representative, as sequencing will enable gradual running lane changes to take place, rather than sudden alterations ${ }^{3}$ which may lead to potentially dangerous driver confusion. However, occasional rapid changes may be necessary to avoid, say, an obstruction on the hard shoulder.

Throughout the series of interviews, a greater number of potential limitations (in comparison to strengths) of the UK approach to HSR were suggested, with all stakeholders having varying concerns regarding safety implications; the safety of drivers who have broken down appears to cause the greatest concern. PACTS considered the length of the Emergency Refuge Areas (ERAs) to be too short to accelerate from and rejoin moving traffic during HSR operation, and too short for vehicle recovery work. The high level of interest in safety is similarly reflected in the news media.

Four of the six interviewees, along with the AA and Association of Vehicle Recovery Operators (AVRO) websites, cited emergency access as a concern. Representatives of the emergency services (ambulance and fire) positioned the issue in terms of the possible increase in incident response times, although the language used during the interview was less overstated and persuasive than might be expected. Some members of the emergency services indeed demonstrated a willingness to accept that HSR may have some favorable safety implications; thereby exhibiting bi-polar attitudes. The news media have displayed a far greater level of concern.

Besides these direct safety considerations, most stakeholder organizations considered motorist 'confusion' to be a potential barrier to the successful implementation of HSR in the UK. The interviewees representing the police and the fire services believed that a red ' $X$ ' should be displayed over the hard shoulder even when all other AMIs are blank, under normal traffic flow conditions. This is a reasonable request, as someone unfamiliar with HSR may mistake four blank overhead AMIs as indicative of the existence of four running lanes (see Fig. 2a). Additionally, the fire service representatives pointed to the A38(M) Aston Expressway tidal flow system, where red ' $\mathrm{X}$ 's are displayed over lanes not for vehicular use. The close proximity of similar, but differently signed, operational lane regimes might also be a source of confusion, with a likely impact on driver behavior.

\footnotetext{
${ }^{3}$ For example, a red ' $\mathrm{X}$ ' over the hard shoulder will not appear 500 meters after an AMI displaying a speed limit over the hard shoulder. Instead, the system protocol allows for a 'move right' warning arrow to be displayed first.
}

The potential confusion surrounding the role of the hard shoulder is one of the main problems emphasized by stakeholders with a sole interest in motoring issues, such as AVRO, the drivers' representative, the police representative, and the RAC. These organizations highlight the importance of the hard shoulder as a safe refuge; something which will be relinquished during HSR, yet is often seen as a design feature which makes motorways safer than other roads. The provision of ERAs as a substitute was only cautiously welcomed by stakeholders, as it has been seen possible that on some occasions drivers will be unable to reach the ERA in a breakdown situation.

A further potential barrier to the success of HSR in the UK, identified by the police representative, is the impact of driver habit; if a driver used the hard shoulder as a running lane yesterday, then $\mathrm{s} / \mathrm{he}$ might attempt to do the same again. Indeed 'habit strength increases with the number of times a behavior has been performed in the past' [19] and, with HSR, this might be compounded by the absence of obvious red ' $X$ 's over the hard shoulder under normal flow conditions and the likely unpredictably of times when HSR is operational.

The police representative also believed that $100 \%$ compliance would be impossible to achieve through the use of signals, with perhaps $5-10 \%$ of vehicles per day not complying (whether consciously or otherwise); on a high speed road this level of non-compliance would reduce the 'success' of HSR. A problem foreseen by the ambulance service representative (although there is no evidence to suggest this has become a reality) is people complying with distant $\mathrm{AMI} / \mathrm{Ss}$ as soon as they become visible, for example by moving onto the hard shoulder; this is potentially dangerous as gantry signs only relate to the carriageway beyond that point.

A short time before this study was held, the drivers' representative focused on highlighting the increased level of driver stress which may result from HSR (in conjunction with variable speed limits), due to the presence of relatively closely-spaced gantries displaying reduced and enforceable speed limits. It was suggested that this will encourage drivers to make constant speed-checks, thereby removing their attention from the new complex motorway situation and reducing the uniformity of decision making which typically makes motorways safer than other roads [20]. Rämä et al. [21] found that fibre-optic variable speed limit signs distracted drivers' attention away from other nearby information signs; this provides some evidence for assertion of the drivers' representative. It is therefore significant that the HA considers reducing driver stress to be a secondary benefit of ATM $[9,22]$.

As mentioned earlier, environmental groups, such as Friends of the Earth (FoE), or the Campaign to Protect Rural England (CPRE), were not interviewed in this study. However, their perspective is highly relevant to the HSR debate and provides an important additional dimension. In environmental terms, HSR does not involve road widening and there is minimal land-take (this could be seen as a benefit by environmental groups). However, HSR may have some longterm consequences that can be seen as negative, mainly the possibility of 'induced traffic'. Induced traffic has been mainly discussed in the context of increasing motorway capacity, where reduced travel costs generate more demand to 
use motorways, increase congestion, and cause an undesired shift from sustainable modes of transport to car transport. This is supported by empirical evidence reported in the UK study by SACTRA [23]: it was found that reducing travel time on a roadway by $20 \%$ increases car traffic volumes by $10 \%$ in the short term and $20 \%$ over the long term.

Environmental groups have a high stake in road capacity increase issues. Induced traffic was used as a grounds for protests against the UK government policy of building motorways. The question about whether HSR could induce traffic growth on the stretches of motorway which it is applied remains open; further research is needed here. However, while there is no empirical evidence on induced traffic as a result of HSR implementation, there are strong parallels between HSR and the provision of new road capacity - both may lead to large amount of induced traffic. Therefore it is not surprising to find the following comment provided on the FoE website, illustrating this side of the HSR debate [24]:

'Extending hard shoulder running is motorway widening by stealth and won't solve our traffic problems. Wider motorways will simply encourage more drivers and cause an increase in carbon dioxide emissions. The Government's feasibility study should look at trialing reduced speed limits without widening in some places to help cut emissions...'

In terms of the findings of the media content analysis, the number of media articles referring to HSR peaked in the second quarter (April-June) of 2003 and the final quarter (October-December) of 2004; these peaks coincided with the publication of an opinion report for the RAC and 'Managing Our Roads' [8], and the publication of the NAO report on congestion [11]. Sentences and themes relating to HSR, in the national media, more commonly appeared in articles focused on the actual concept of HSR, whereas those in the local media appeared more often in articles focused on road safety (Fig. 3). The road safety focus diminished over time, so that from July 2004 news articles referring to HSR were focused more on traffic congestion. The main perceived reason for the piloting of HSR was its role as a congestion reducing measure; few articles suggested HSR is a cost-cutting measure, or that it is being piloted simply to test innovative uses for the hard shoulder.

There is no clear trend in how HSR as a concept has been portrayed in both national and local news media since mid2002, although a slightly more favorable portrayal (neutral or more positive) is evident in the latter months of 2004. The way in which HSR was portrayed varied substantially between national and local news articles; while national media generally viewed it from neutral to slightly positive, local media were often highly negative (Fig. 4). In addition, 64\% of local news articles used emotive overstated language (compared to $19 \%$ of national articles), in many cases linking HSR with the potential for more accidents, injuries and deaths. It was found that the national media have recently provided a more positive interpretation of the concept of HSR than the local media.

A number of local newspapers, possibly partly due to their proximity to the M42, have engaged in a discourse which represents HSR as detrimental to the safety of the UK motorist. Local newspapers further away from the M42 have also provided negative coverage; for example, on the $9^{\text {th }} \mathrm{Jul}$
2003, Plymouth's 'Western Morning News' began a front page motoring feature article with 'Government plans to ease congestion by allowing drivers to use motorway hard shoulders will result in more accidents, injuries and deaths'. Representing HSR in this way, is likely to have assisted in the creation of a substantial level of negative opinion amongst some sectors of the general public, before the pilot commenced. The way in which public opinion has been shaped

(a) National

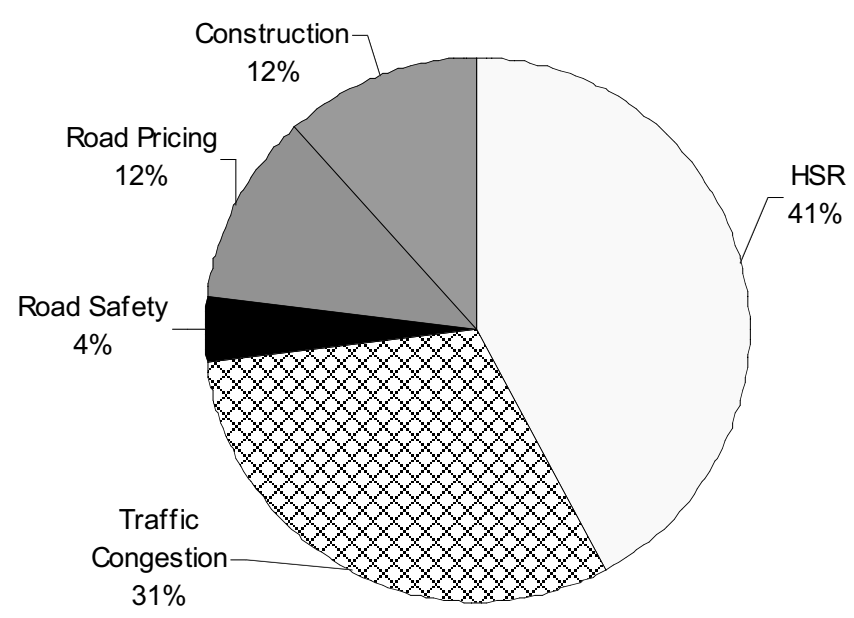

(b) Local

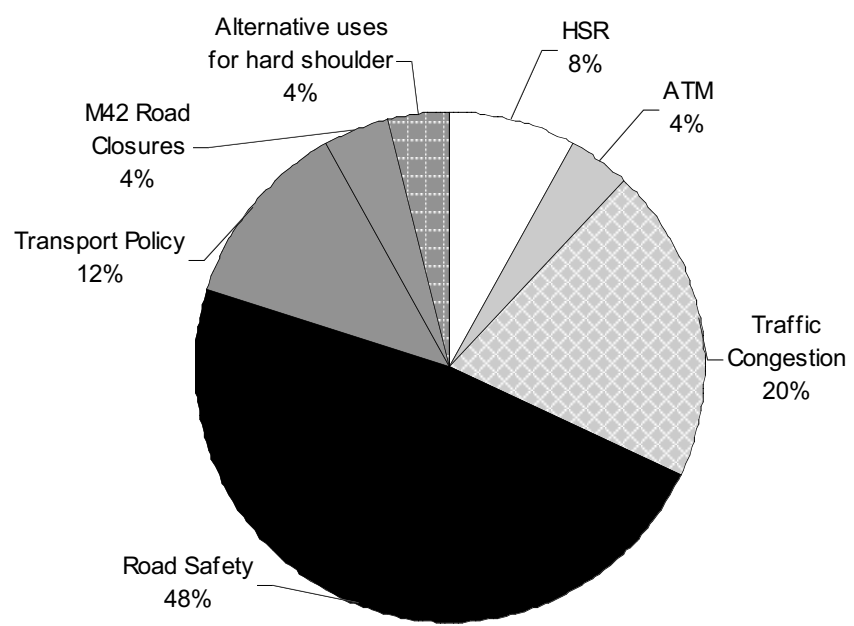

Fig. (3). Overall focus of documents containing references to HSR.

by news reports is worthy of further research, although was outside the scope of this project. However, a general indication of public opinion is partly demonstrated on internet motoring issue discussion boards (see Table 2). While these responses cannot be interpreted as fully representative of public opinion, they are indicative of attitudes currently held on HSR.

It is evident, from the elaboration provided in the first example (see Table 2), that strong negative attitudes exist towards HSR, primarily on safety grounds. Significantly, these strong uni-polar attitudes are likely to be more resistant to change and more persistent over time [25]. Although strong positive attitudes towards HSR do exist, positive attitudes tend to be weaker and bi-polar, additionally recognizing the presence of limitations (see example in Table 2 ). 
Positive coverage of HSR in national newspapers during the latter months of 2004 might be attributable to the NAO's critical report on the problem of road congestion in the UK. However, national media articles which referred to HSR more positively (without identifying any limitations) tended to be shorter on average; 288 words compared to the news media sample average of 577 words. Most of the positive national articles tended also to only briefly refer to HSR in the context of another topic, such as road pricing or road construction. Overall, the news media have therefore elaborated more on the limitations of HSR.

(a) National

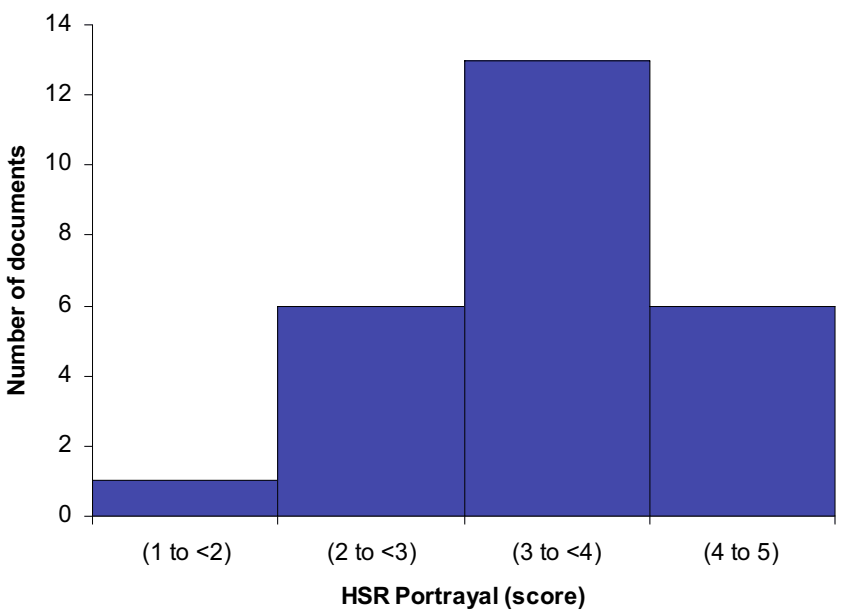

(b) Local

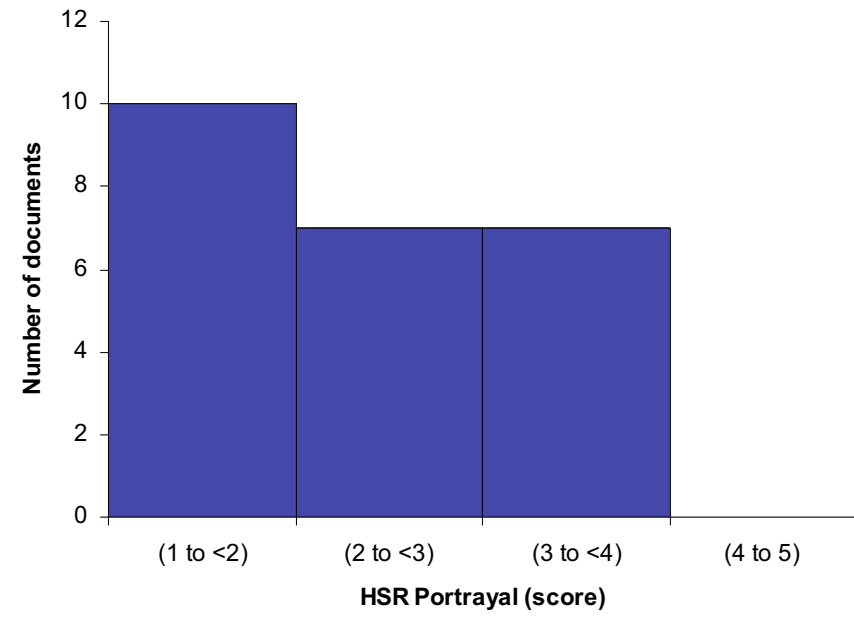

Fig. (4). Portrayal of HSR in news media articles; (1-highly negative, 2-slight negative, 3-neutral, 4-slight positive, 5-highly positive).

Table 2. Internet Discussion Board Responses

'Using the hard shoulder is a cheapskate and ill considered approach to a problem caused by underinvestment...I hope and pray that this insane idea to use the hard shoulder as a running lane is proved a failure before too many people are killed.' (15 ${ }^{\text {th }}$ July 2005)

'Notwithstanding the other arguments, I cannot see how this is going to be too problematic - provided the signage is good and drivers know that they have to vacate the hard shoulder in good time.' $\left(15^{\text {th }}\right.$ July 2005)
In terms of informing the public about the nature and purpose of HSR trials (or ATM more generally) in the UK, official information provided to the public consists of two HA leaflet type publications (HA23/05 and HA76/05) available through the HA Information Line and occasionally at motorway service stations, as well as the HA website. However, unless members of the public were interested (and knowledgeable) enough to seek this information, it is unlikely that these publications have reached a wide general audience. Therefore, it can be argued that news articles on ATM, printed in both local and national newspapers, may have provided most 'information' on HSR before it became operational.

In examining the potential acceptability of UK HSR, stakeholders were asked to consider whether any additional information might be required for drivers to successfully adapt to the new motorway regime; see Table 3. Although four stakeholders stressed the need to avoid driver information overload, the police representative and PACTS suggested some limited additional information. The overarching aim of improving on-site HSR information provision is to reduce the level of confusion anticipated by a number of organizations. The potential impact of appropriate on-site information provision is discussed later, in relation to the Theory of Planned Behavior (TPB) [26] and mitigation, discussed in the next section.

On-site information is only one element of driver information which could be considered for HSR. All six interview respondents believed that public awareness would be crucial for the 'success' of the M42 ATM pilot; success is generally referred to by stakeholders in terms of congestion reduction with a neutral, or positive, impact on safety. Five of the six respondents saw the need for a major national TV public awareness campaign prior to the launch of the HSR pilot, accompanied by radio campaigns and leafleting where appropriate. Stakeholders suggested that campaigns should explain ATM, sign meanings, and procedures to follow in an emergency, although it was suggested that these campaigns should not take place too far in advance of any trial, as this would lessen their impact.

PACTS would like to see the Highway Code amended to reflect the ATM pilot and changing role of the hard shoulder under HSR; shortly before HSR was piloted, the Highway Code still only referred to the safety functions of the hard shoulder. Again, this information is aimed to raise awareness and therefore reduce confusion, in order to increase the benefits of ATM, and the new HSR regime more specifically ${ }^{4}$.

\section{DISCUSSION: DISCOURSE, ATTITUDE AND BE- HAVIOR}

Socio-cognitive models have provided researchers with a theoretical framework to guide many of the studies that have sought to predict and explain public and political acceptability of new schemes and policies. The acceptability of HSR by road users and other stakeholders can be seen primarily as determined by attitudes. Previous research has provided empirical support for social psychological Theory of Planned Behavior (TPB) [26] application to driving behavior insofar

\footnotetext{
${ }^{4}$ ATM aspects, including HSR, are addressed in the latest version of the Highway Code, published after this study was completed.
} 
Table 3. Potential Informational and Educational Requirements of UK Drivers for Successful Adaptation to HSR

\begin{tabular}{|c|c|c|c|}
\hline & Scheme Awareness & Driving Responses & On-Site Information \\
\hline $\begin{array}{l}\text { Drivers Representa- } \\
\text { tive }\end{array}$ & $\begin{array}{l}\text { Major local advertising campaign (radio, } \\
\text { TV, leaflets). National TV campaign - } \\
\text { sign meanings and what to do. }\end{array}$ & - & $\begin{array}{l}\text { Matrix signs locally on approaches, for } \\
\text { example, 'HSR scheme ahead'. }\end{array}$ \\
\hline Police Representative & $\begin{array}{l}\text { National TV advertisement about ATM. } \\
\text { More information in the West Midlands } \\
\text { area, but need to roll it out nationally due } \\
\text { to NEC. }\end{array}$ & $\begin{array}{l}\text { Overcome driver habits through } \\
\text { education. }\end{array}$ & $\begin{array}{c}\text { Possibly too much information already, but } \\
\text { need red 'X's to stop people driving on } \\
\text { hard shoulder. }\end{array}$ \\
\hline PACTS & $\begin{array}{l}\text { TV and local radio advertising. } \\
\text { Refer to it in Highway Code - useful for } \\
\text { learners to have an understanding. } \\
\text { Pass Plus could incorporate it. }\end{array}$ & $\begin{array}{l}\text { Response of UK drivers will de- } \\
\text { pend on how convincing the gov- } \\
\text { ernment is at explaining the reasons } \\
\text { for HSR. }\end{array}$ & $\begin{array}{l}\text { Ensure information is up-to-date and real- } \\
\text { time. } \\
\text { Perhaps an occasional sign saying 'in case } \\
\text { of emergency use lay-by'. } \\
\text { Need to avoid information overload. }\end{array}$ \\
\hline $\begin{array}{l}\text { Haulage Industry } \\
\text { Representative }\end{array}$ & $\begin{array}{l}\text { Need high level of driver education and } \\
\text { awareness - basic sheet of paper outlin- } \\
\text { ing sign meanings as a minimum. } \\
\text { Awareness of new safe refuges needed. }\end{array}$ & $\begin{array}{l}\text { One bit of education that applies } \\
\text { even more with HSR is lane disci- } \\
\text { pline - expand into a 'use the avail- } \\
\text { able space properly' campaign. }\end{array}$ & $\begin{array}{l}\text { Any more information may be confusing - } \\
\text { keep it simple. Frankly, people need to } \\
\text { know if they can go on the hard shoulder. }\end{array}$ \\
\hline $\begin{array}{l}\text { Ambulance Service } \\
\text { Representative }\end{array}$ & $\begin{array}{l}\text { Advance publication of what is going to } \\
\text { happen, within a few weeks of it starting. } \\
\text { Radio and TV (not leafleting), as a lot of } \\
\text { traffic on M42 is transient from one area } \\
\text { of England to another. }\end{array}$ & - & - \\
\hline $\begin{array}{l}\text { Fire Service Repre- } \\
\text { sentative }\end{array}$ & $\begin{array}{l}\text { TV, newspaper, internet, information at } \\
\text { ports, leafleting at motorway services, } \\
\text { mail shots to homes; need to explain } \\
\text { ATM. }\end{array}$ & $\begin{array}{l}\text { Publicize the use of cameras and } \\
\text { enforcement for HSR. }\end{array}$ & $\begin{array}{l}\text { When it's not in use there should be a red } \\
\text { X, as with the Aston Expressway. }\end{array}$ \\
\hline
\end{tabular}

as attitudes, subjective norms, and perceptions of control are positively associated with intentions to conduct specific actions and make specific decisions (see, for examples [26,27]). Moreover, measuring attitudes can help to describe and understand the degree of acceptance or intentions people have to adapt or otherwise to a new scheme or policy.

It might therefore be possible to apply TPB in examining potential (non-) compliance with the HSR variable message signing and temporal restrictions planned for the M42. The TPB's suggestion that behavioral intentions are influenced by attitudes, perceived social pressures (subjective norms), and perceived behavioral control, coupled with the moderating effect of habit, are all directly related to this research project; perceived social pressures can be linked to the impact of various discourses on perceptions of HSR.

Furthermore, although the TPB has not been developed for general use in behavioral analyses, it can be slightly modified to provide a framework to help understand how attitudes might impact on driver behavior and the ways in which potential limitations might be mitigated (see Fig. 5). This is a slight modification of the TPB as suggested by Ajzen [26], which refers to the attitude towards a particular behavior, as opposed to the attitude towards a concept. A greater understanding of these aspects will assist in assessing the potential acceptability of HSR as a technique for helping to alleviate motorway congestion in the UK. Ultimately, responses towards the acceptability of HSR will have implications on the success of the pilot and support for its wider implementation.

There has been no detailed research undertaken into the validity of the models which follow from this framework; however, the models demonstrate linkages which could be investigated in future research into HSR, or ATM more generally. The suggested models could be referred to, perhaps in evaluating the impact of the HSR pilot, with data collection relating to the behavioral response impacts of HSR and analysis tracing those impacts back to ascertain whether any clear relationship exists between attitudes and behavioral responses.

Bohner and Wänke [25] consider the types of attitude response, namely 'affective', 'behavioral' and 'cognitive'. In this research, the affective and cognitive responses relate to the 'attitude' element of the TPB. Behavioral responses relate to driver behavior and the resulting impact on the safety implications (or success) of the HSR pilot; the outcome of the TPB model.

The negativity of many news reports and, as mentioned earlier, the strong negative uni-polar attitudes which did exist among members of the public, may give rise to a variety of affective and cognitive responses. The possible responses encompassed by these negative attitudes were suggested during the stakeholder interviews, namely feelings of confusion, safety concerns and driver distraction. These attitude responses may influence behavioral intentions and subsequently impact on actual behavior.

Cognitive processes that give rise to confusion, concern, or distraction (separate to any consequential behavior) can be considered as potential barriers to the successful operation of HSR in the UK, primarily because public support for its wider implementation may not materialize. In the absence of public support, the HA would face difficulty in convincing decision-makers of the merits of expanding the pilot pro- 


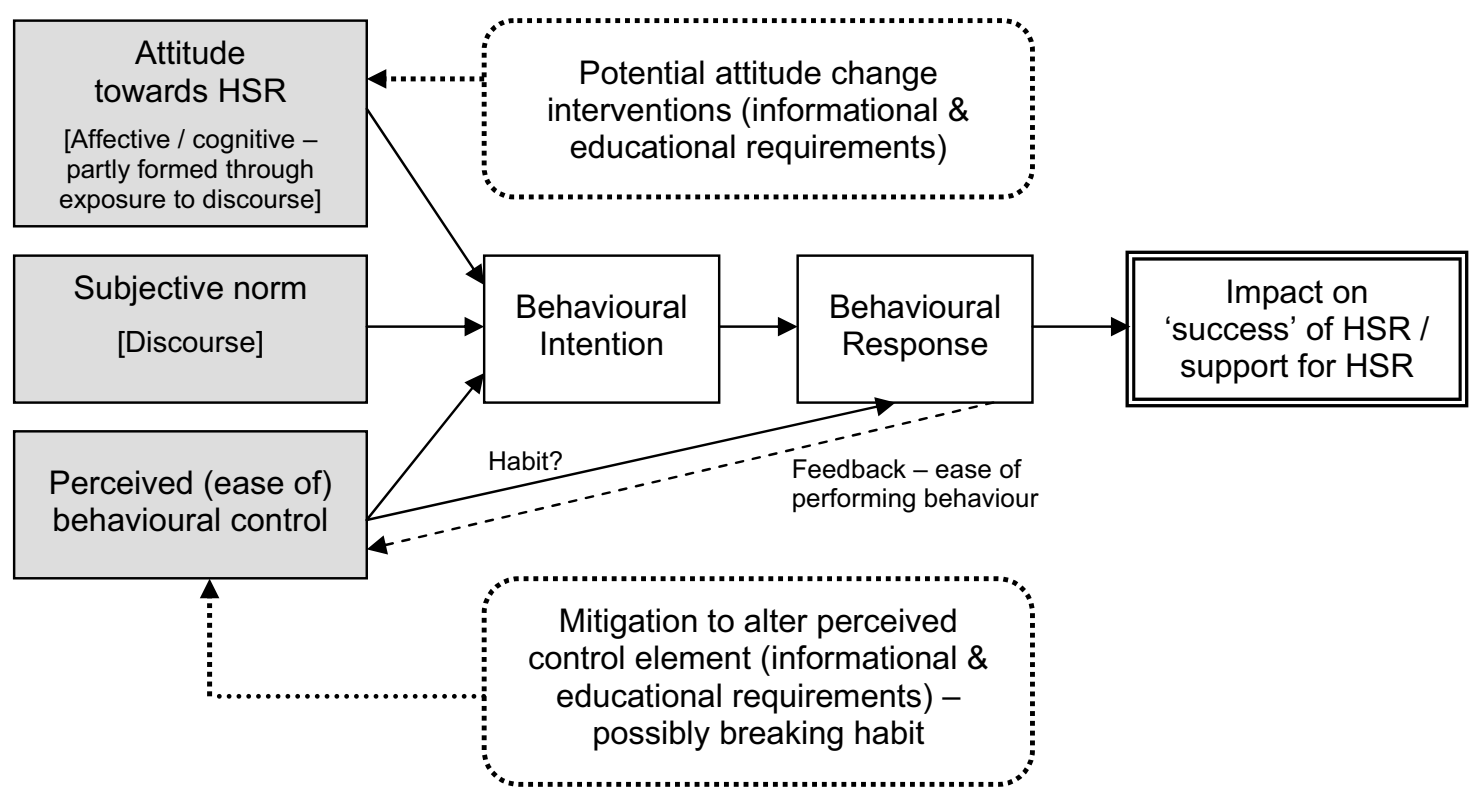

Fig. (5). HSR behavioral process framework - modification of the Theory of Planned Behavior according to Ajzen [26].

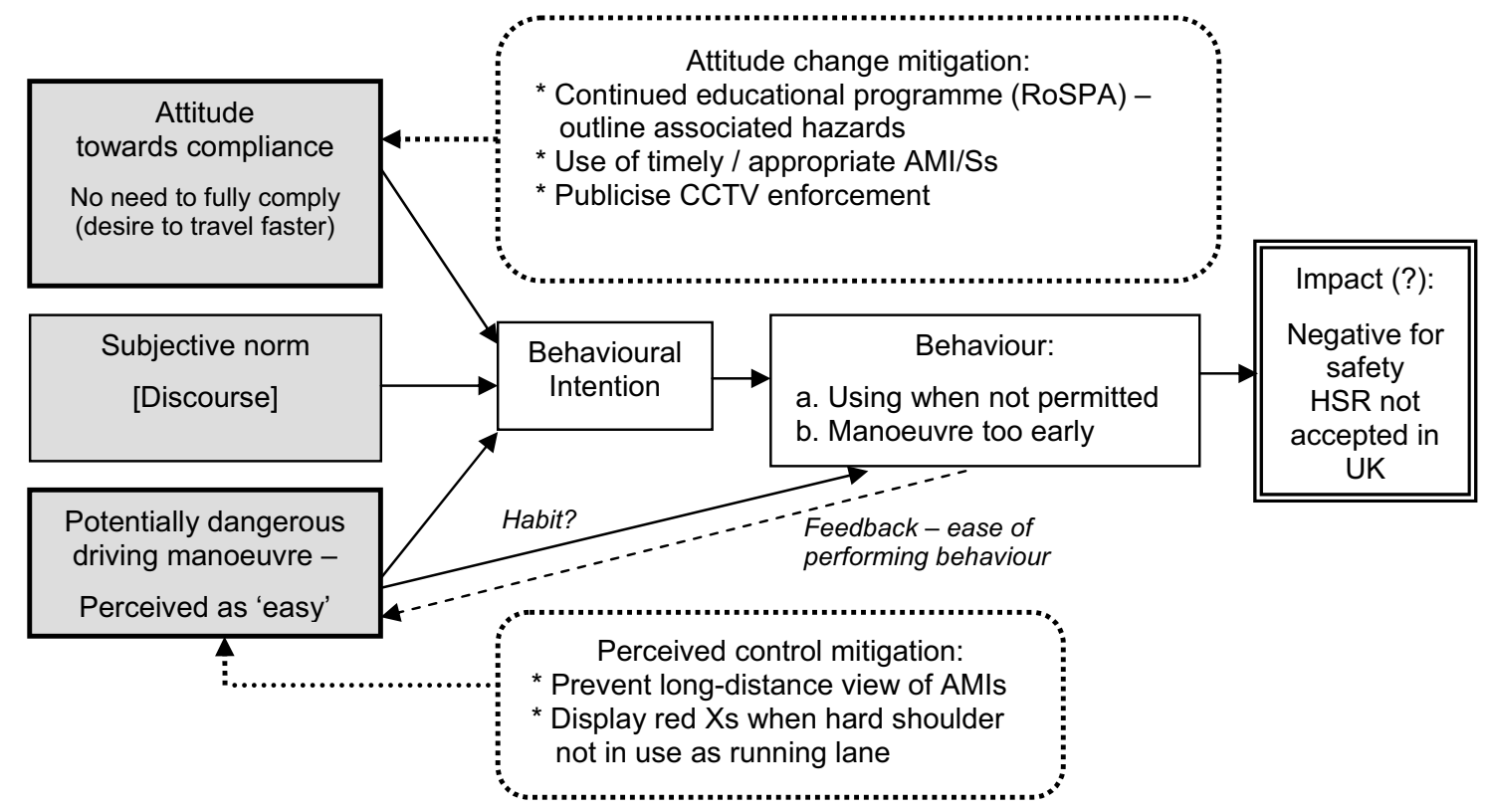

Fig (6). Applying the Theory of Planned Behaviour to compliance with AMIs and AMSs relating to HSR.

gram, or permanent implementation in the longer-term. It is therefore important that the public are properly informed about HSR, so that negative affective and cognitive attitude responses are not automatic.
Attitudes towards the perceived uneasy relationship between HSR and what constitutes an acceptable level of road 
infrastructure investment, held by the drivers' representative and haulage industry representative, might prove more problematic for the acceptability and future of HSR. It may be hard to convince these stakeholders, who subscribe to the discourse of HSR as an unacceptable 'cheap' method of increasing motorway capacity, of the benefits of HSR even if it is found to be an appropriate technique for the UK. This is partly due to the stakeholders' interest in substantial road infrastructure investment to improve conditions for motorists and the road freight industry. The impact of this discourse, if it were to prevail, might be that it becomes normal for the public to perceive HSR as 'second best' to road widening, thereby always viewing it in a negative manner even if the scheme proves to be successful in reducing both congestion and accident severity.

Another key discourse, used primarily by the news media and on some stakeholders' websites, represents HSR as detrimental to the safety of the UK motorist, often through the use of persuasive and emotive language. Although it is not possible to properly interpret the reasons behind the production of such a discourse by reference to the texts alone, it could be argued that the producers (whether stakeholders or reporters) aim to create a substantial level of negative opinion amongst the general public, as part of a wider discontent with recent transport policy affecting the private motorist. While the texts themselves cannot automatically bring about changes in people's behavior in a simple mechanical causality [28], heightened concerns over the safety of HSR may give rise to attitude responses that subsequently impact on driver behavior.

Fig. (6) applies the TPB to understanding the limitations identified for compliance with the AMI/Ss on the M42 ATM pilot section. Behavior such as using the hard shoulder as a running lane outside HSR operation, or following the instructions of distant $\mathrm{AMI} / \mathrm{Ss}$ too far in advance, might also result from a behavioral intention to make such a maneuver, and not just from confusion. In accordance with the TPB, the strength of the behavioral intention can be reduced by addressing one or more of the three main influences; perceived behavioral control (ease), attitude toward the behavior, or subjective norm. Mitigation measures that address these influences, some of which are advocated by stakeholders (see Fig. 6) may therefore help to minimize potentially dangerous driving maneuvers and make HSR more acceptable in the UK.

Other mitigation measures that could be considered for HSR in the UK include static HSR times, as opposed to variations which might prove to be unpredictable from the driver's point of view. The hard shoulder is open only at fixed times $(3-7 \mathrm{pm})$ on the A7 near the Göttingen interchange in Germany [12]. However, the police representative pointed out that this is not necessarily a sensible option for simplifying the regime for two reasons; firstly traffic flows vary on motorways in the UK and secondly, if an incident occurs that blocks the carriageway upstream, the traffic may reach the HSR section later than usual, when the fixed time period has expired.

\section{SUMMARY AND RECOMMENDATIONS}

In general, the strength of stakeholders' attitudes towards the benefits of HSR tends to be weaker than that for the limi- tations. In addition, the suggested strengths tend to be generic to HSR, rather than specific to the UK approach, and may be more attributable to complementary ATM measures such as variable speed limits which, arguably, assist in traffic flow regulation to a greater extent.

Stronger attitudes exist amongst stakeholders towards potential barriers to the successful operation of HSR in the UK, with notable use of persuasive and emotive language. This is less pronounced from the members of the emergency services who demonstrated a bi-polar attitude towards safety issues. Nevertheless, safety was the greatest concern of stakeholders, particularly breakdown difficulties (including ERA length) and incident response times. There are potential problems relating to motorist compliance and it is also not clear if HSR (with variable speed limits) will achieve its secondary aim of reducing driver stress.

In relation to information provision, recommendations to the promoting highway authority for increasing the acceptability of HSR, by responding to prevailing attitudes and discourse, are shown below; however, further investigation into drivers' attitudes towards HSR is necessary to confirm the suitability of such recommendations. These are likely to be transferable to other recent controversial transport planning policy initiatives, such as the use of HOV lanes on motorways.

(1) Ensure that the news media are appropriately briefed, to counter the prevailing negativity.

(2) Basic information should be supplied to as many drivers as possible, along the lines of the existing ATM publications HA23/05 and HA76/05.

(3) Wider information coverage using a range of media, including local radio and national TV.

(4) Working with the emergency services, information should demonstrate why the safety risks might be lower than perceived.

(5) Produce a balanced non-technical summary document on the benefits and disbenefits of HSR. This should then be released pro-actively to the press, so that a more balanced discussion of HSR can be developed in the news media.

In terms of general driver information provision and if wider piloting is to take place, it should be highlighted to drivers that hard shoulder use will be enforced; this may assist in addressing the compliance attitude element of the TPB model (see Fig. 6).

Overall, although there are a number of potential limitations to HSR, there appear to be relatively few reasons why HSR cannot become successful and acceptable in the UK. The possible compliance model (Fig. 6), based on stakeholders' suggestions and involving the consideration of discourse and attitudes, suggests that a number of potential problems might be due to hazardous driving behavior. However, appropriate mitigation should reduce accidents and the need for crucial emergency access. This is likely to improve the level of acceptability of HSR as a technique.

The remaining acceptability problems seem likely to relate to breakdown and emergency access. Emergency services representatives appear to be less concerned than the me- 
dia. Nevertheless, the impact of UK HSR on emergency access cannot be certain until trials have been conducted. Perhaps it would be sensible to conduct a live emergency access trial (moving traffic out of running lanes using AMIs) with no casualties present. Any early problems might then be addressed in order to avoid unnecessary fatalities in future. Similarly, there is a need to pursue wider piloting of HSR in order to increase the validity of the conclusions, as only then will it be possible to provide a definitive answer to the question of the acceptability and appropriateness of HSR in the UK.

Since late 2006 (after study completion) a pilot ATM/ HSR scheme has been operating on the M42, which the Transport Secretary, Ruth Kelly, recently pronounced as successful [29]. Following the pilot, new ways of managing motorway traffic (including HSR) will be implemented as part of a $£ 150 \mathrm{~m}$ scheme on the motorway box around Birmingham, and a feasibility study will be undertaken to consider if similar schemes could help to beat congestion on other parts of the motorway network.

In terms of future research, it will be necessary to examine actual public awareness and support, with further indepth behavioral research into drivers' attitudes and intentions. The research reported in this paper was conducted before the piloting of the M42 scheme.

Future research will need to look at empirical evidence on the effectiveness of HSR schemes and their impacts on congestion levels, environment and safety. Stakeholders and the general public may become more informed and more aware to the long-term consequences of HSR, such as the possible generation of induced traffic. Long-term impacts might have a strong effect on attitudes towards HSR and the acceptability of such schemes.

This research addressed HSR from a policy perspective and did not attempt to quantify its costs and benefits. Costbenefit analysis of HSR would quantify the benefits in the UK. Benefits may include time savings and accident reductions (through reduced congestion and smoothing of traffic flows), while the costs of HSR may include an increased number of accidents due to different hard shoulder usage, and capital implementation and operating costs. Another important element of the cost-benefit analysis is the external costs associated with HSR such as air pollution and greenhouse gas emissions.

Empirical research into support (or otherwise) for the suggested TPB models, regarding the relationship between attitudes, discourse and behavior, may prove worthwhile for developing behavior mitigation measures.

\section{DISCLAIMER}

The intention of this research project was not to critique the HA themselves, as they have been encouraged to rapidly develop congestion reducing measures as a result of criticism from both the National Audit Office and Commons Public Accounts Committee. The research also does not question whether the HA was correct in making a decision to pilot $\mathrm{HSR}$, as the piloting of innovative techniques is a necessary part of finding ways to move forward in transport planning. Although this research only specifically mentions the Highways Agency in England, and not the equivalent national trunk road agencies in Northern Ireland, Scotland, or Wales, it may be assumed that findings from both the M42 pilot and this research will be transferable across all UK motorways, as a result of engineering and cultural similarities.

Interviews were undertaken with individual members of stakeholder organizations; therefore their opinions should not be assumed to be fully representative of those organizations, but as informed through their membership of that organization.

\section{REFERENCES}

[1] R. Eddington, The Eddington Transport Study. Main Report: Transport's role in sustaining the UK's productivity and competitiveness. London: TSO (The Stationery Office), 2006.

[2] DfT, Transport demand to 2025 and the economic case for roadpricing and investment. London: TSO (The Stationery Office), 2006.

[3] DETR, A New Deal for Transport: Better for Everyone, London: HMSO, 1998.

[4] IHT, Transport in the Urban Environment, London: IHT, 1997.

[5] C. A. O'Flaherty, "Road capacity and design-standard approaches to road design" in Transport Planning and Traffic Engineering, C. A. O'Flaherty, Ed., London: Elsevier Butterworth-Heinemann, pp. 281-298, 1997.

[6] C. A. O'Flaherty, "Geometric design of streets and highways" in Transport Planning and Traffic Engineering, C. A. O'Flaherty, Ed., London: Elsevier Butterworth-Heinemann, pp. 320-355, 1997.

[7] DETR, A New Deal for Trunk Roads in England, London: HMSO, 1998.

[8] DfT, Managing Our Roads, London: TSO (The Stationery Office), 2003.

[9] HA, Active Traffic Management (ATM) Project M42 Junctions 3A-7 [Online], London: Highways Agency, 2004. Available: http://www.highways.gov.uk/roads/projects/4685.aspx [First accessed 19/01/05, last accessed 9/3/08].

[10] R. Thomas, "Can the Dutch teach us how to manage motorway traffic?”, Local Transport Today, vol. 24, pp. 10-11, July 2003.

[11] NAO, Tackling Congestion by Making Better Use of England's Motorways and Trunk Roads, London: National Audit Office, 2004.

[12] M. Shahin, F. Engelmann, and B. Friedrich, "Using the motorway hard shoulder in congestion to allow drivers to exit", Traffic Engineering \& Control, vol. 44, no. 7, pp. 258-263, 2003.

[13] W. Berger, and P. Maurer, "Emergency bays versus emergency lanes on motorways - A cost benefit analysis", Traffic Safety on Two Continents - 10th International Conference, Mälmo, 09/99, 1999.

[14] G. Kellermann, "Experience of using the hard shoulder to improve traffic flows", Traffic Engineering \& Control, vol. 41, no. 10, pp. 412-414, 2000

[15] USDT, Safety Effects of Using Narrow Lanes and Shoulder-Use Lanes to Increase the Capacity of Urban Freeways: Summary Report, McLean: Turner-Fairbank Highway Research Center, 2005.

[16] J. Whitelaw, "Shouldering responsibility", New Civil Engineer, pp. 37-38, September, 2002.

[17] I. Summersgill, J. V. Kennedy, J. M. Sharples and M. J. Frew, Safety on Hard Shoulders on Dual Two-Lane and Three-Lane Motorways, PPR017, Wokingham: TRL, 2004.

[18] R. Gifford, Tackling congestion on motorways and trunk roads in England [Online], letter from PACTS to K. Holden at National Audit Office on 11 July 2003.

[19] M. A. Elliot, J. C. Armitage, and C. J. Baughan, "Drivers' Compliance with Speed Limits: An Application of the Theory of Planned Behaviour", J Appl Psychol., vol. 88, no. 5, pp. 964-972, 2003.

[20] P. Baldwin, and R. Baldwin, Eds., The Motorway Achievement Volume 1 - The British Motorway System: Visualisation, Policy and Administration, London: Thomas Telford, 2004.

[21] P. Rämä, J. Luoma and V. Harjula, "Distraction due to variable speed limits", Traffic Engineering \& Control, vol. 40, no. 9, pp. 428-430, 1999

[22] HA, M42 Active Traffic Management, Motorway Closures 2004: Background Paper and Explanatory Note for the Draft Statutory Instruments Consultation Process [Online], London: Highways Age- 
ncy, 2004. Available: http://www.highways.gov.uk/roads/3080.aspx [First accessed 11/01/05, last accessed 9/3/08].

[23] SACTRA "Trunk Roads and the Generation of Traffic", Standing Advisory Committee on Trunk Road Assessment, UKDoT, HMSO, 1994,

[24] FoE. "Press Release - Hard Shoulder Running: Friends of the Earth Comment". Friends of the Earth, 25 October 2007. Available: $\mathrm{http}: / /$ www.foe.co.uk/resource/press_releases/hard_shoulder_running frie_25102007.html [Last accessed 30/4/2008].

[25] G. Bohner, and $\bar{M}$. Wänke, Attitudes and Attitude Change, Hove: Psychology Press Ltd, 2002.
[26] I. Ajzen, "From intentions to actions: A theory of planned behaviour" in Action-Control: From Cognition to Behaviour, J. Kuhl, and J. Beckman, Eds., Heidelberg: Springer, pp. 11-39, 1985.

[27] S. Bamberg, D. Rolle, and C. Weber, "Does habitual car use not lead to more resistance to change of travel mode?" Transportation, vol. 30, no. 1, pp. 97-108, 2003.

[28] N. Fairclough, Analysing Discourse: Textual Analysis for Social Research, London: Routledge, 2003.

[29] GNN (Government News Network), "Kelly Announces New Ways to Beat Motorway Jams", 25 October 2007. Available: http://www. gnn.gov.uk/environment/mediaDetail.asp?MediaDetailsID $=220410$ $\&$ NewsAreaID $=2 \&$ ClientID $=202 \&$ LocaleID $=2 \quad$ [Last accessed $9 / 3 / 08]$.

(C) Antoci et al.; Licensee Bentham Open.

This is an open access article distributed under the terms of the Creative Commons Attribution License (http://creativecommons.org/licenses/by/2.5/), which permits unrestrictive use, distribution, and reproduction in any medium, provided the original work is properly cited. 